\title{
Effect of Clamping Torque on Large Deflection Static and Dynamic Response of a Cantilever Beam: An Experimental Study
}

\author{
Soumen Mondal ${ }^{1, a}$, Sushanta Ghuku ${ }^{2, b}$ and Kashi Nath Saha ${ }^{3, c^{*}}$ \\ ${ }^{1,2,3}$ Mechanical Engineering Department, Jadavpur University, Kolkata-700032, India \\ amondalsoumen94@gmail.com, binfo.sghuku@gmail.com, ${ }^{{ }^{*}}$ kashinathsaha@gmail.com
}

Keywords: Experimental work; strain measurement; deflection measurement; loaded natural frequency measurement; clamping effect.

\begin{abstract}
The present paper reports an experimental study on the effect of finite clamping on static and dynamic characteristics of cantilever beam. The experiment is carried out with two different beams, each of which is clamped at two different locations resulting in two different geometry settings. Under each of these four settings, specimen is clamped under two different torque ratings giving rise to different finite clamping effect. Under the eight settings, coordinates of tip point under static loading are measured directly using scales and plumb at each load step; whereas, complete deflection profiles of loaded beam under each static load step are obtained through postprocessing of images captured during experimentation. Such image processing is carried out manually using AutoCAD ${ }^{\circledR}$ and in-built AutoLISP ${ }^{\circledR}$ software. Strain measurements at each static load step are carried out by using strain gauge, a universal data acquisition system and the associated Catman Easy ${ }^{\circledR}$ software. To obtain loaded free vibration characteristics, loaded beam under each setting is disturbed by a rubber hammer and its dynamic response is recorded from strain gauge signal through Catman Easy ${ }^{\circledR}$ software. These dynamic strain readings of loaded beam are post-processed and FFT plots are generated in MATLAB ${ }^{\circledR}$ software and first two loaded natural frequencies of beam under each setting are obtained. Finally, effects of clamping torques on the static strain and deflection results and loaded natural frequencies for beam settings with the four different thickness to length ratios are reported in a suitable manner. The result reported may be useful as ready reference to develop a theoretical model of clamped beam like structures incorporating the effect of finite clamping.
\end{abstract}

\section{Introduction}

It is known that cantilever beam is extensively used as structural member and machine elements in civil and mechanical engineering applications. Traditionally stress and deflection response of cantilever beam under static loading are analyzed using Euler-Bernoulli linear model and dynamic behavior is analyzed by Euler-Lagrange equation considering zero degrees of freedom of deformation at the clamped end. However, the actual mechanical behavior of a cantilever beam cannot be predicted by such linear beam models as all structures involve some nonlinearity. Within elastic limit of beam material, nonlinearity is generally enters in the model of cantilever beam from nonlinear kinematics of deformation [1]. In addition, infinite clamping, as generally considered in theoretical models, is not possible for any clamped beam-like structures. Such difference between actual mechanical behavior and theoretical model of cantilever beam in terms of clamping effect become prominent under large deflection [2].

Theoretical and experimental studies on geometric nonlinearity of cantilever beam under static loading are presented by many researchers [1-4]. Most of the experimental works on strain measurement in beam-like structures involve strain gauge technique [3,5]. Whereas, many other strain measuring techniques like, extensometer, machine crosshead motion are explained by Motra et al. [6]. On the other hand, displacement measurement through some direct measurement technique using several sensors like LVDT, dial gauge etc. are presented in a paper by AhuettGarza et al. [7]. Measurement of deflection profile using image processing technique is used and explained by Ghuku and Saha [2, 3]. Pai et al. [8] presented an experimental and numerical analysis 
of finite-element model for anisotropic beam under large deformation. Mujika [9] observed effect of shear and local deformation under low to high range of strain. Dorogoy and Rittel [10] experimentally and numerically investigated elasto-plastic beam bending under impact loading.

Large numbers of research papers are available in the basic dynamic behavior of an end loaded cantilever beam. Most of the reported works are numerical and analytical investigations [1114], whereas pure experimental work is few some of such relevant papers are reviewed and presented here. Prasant et al. [15] reported experimental modal analysis of rectangular cantilever beam using accelerometer sensor and NI cDAQ-9171. Prasad and Seshu [16] studied experimentally modal characteristics of beam made of different materials such as Steel, Brass, Copper and Aluminum. Krishna and Padmanabhan [17] observed second mode response of flexible cantilever beam under vibro-impact at free end. Lasowicz and Jancowski [18] studied modal characteristics of a composite aluminum cantilever beam with a polymer adhesive and reported observations on effect of polymer adhesive on damping properties. Ilyas et al. [19] investigated pull-in characteristics, pull-in time and natural frequencies of electrostatically coupled silicon micro-beam for different input voltage. Armandei et al. [20] carried out free vibration experiment in bending mode with bamboo slices of different wall-thickness and studied variation of mechanical properties through frequency spectrum analysis. Hobeck and Inman [21] reported experimental observations on flow-induced vibration of dual cantilever flutter using laser displacement sensor for tip deflection measurement. Wahrhaftig and Brasil [22] studied resonate frequency of largely deformed cantilever beam using strain gauge and accelerometer. Anderson et al. [23] investigated first two modal response of parametrically excited slender cantilever beam using DC LVTD and accelerometer, and experimentally verified the dominating effects of nonlinear curvature in first mode response and nonlinear inertia in second mode of response. Zembaty et al. [24] investigated flexural vibration of cantilever beam using rotation rate sensor and strain gauge. Ikeda et al. [25] developed a high precision pressure sensor fabricated from silicon sensor and two resonant strain gauges. Djordjevich and Boskovic [26] prepared a fiber-optic sensor to measure deflected surface or curvature. Xiao et al. [27] investigated strain sensing property of carbon black filled cement-based composite (CBCC) sensor under bending at three different zones, i.e. uniaxial tension, combined compression and shear, uniaxial compression. Zhou et al. [28] performed two sets of modal tests with uniform and non-uniform thin channelled cantilever beams and obtained natural frequencies and associated mode shapes using accelerometer and LMS SCM-05 data acquisition device in association with poly-reference least squares method. Roncen et al. [29] developed an experimental set-up to perform forced vibration experiment with clamped-clamped beam and experimentally obtained nonlinear frequency-response of beam under harmonic excitation. Finally, they compared the experimental results with numerical ones obtained through nonlinear models based on methods of Harmonic Balance and non-intrusive polynomial chaos expansion technique.

Theoretical and experimental works on static and dynamic analysis of cantilever beam and its equivalent structural member considering nonlinearity due to large deflection only are reported in huge numbers. On the other hand, experimental work is rarely found. Similarly the effect of finite clamping in case of practical clamped beam-like structures are also reported rarely. Such effect becomes prominent under large deflection and in the present experimental work, effect of finite clamping torque on static and dynamic response of cantilever beam of different slenderness ratio is investigated. Variations observed in the static deflection and strain results and loaded natural frequency results with varying clamping torque are reported in an appropriate form.

\section{Experimental Set-Up and Procedure}

The experimental set-up along with some measurement instruments is presented in Fig. 1 through photographs taken from the front and right side of the set-up. In addition, main components of the set-up are shown separately through a schematic diagram in Fig. 2. As shown in the figure, the bottom plate is grouted on top of RCC base and on this bottom plate four support columns (item 5) are fixed with the threaded joint. Another plate (item 4) is mounted on top of the columns, which holds circular nut (item 3). A specially designed spindle (item 2) is assembled with the circular nut 
(item 3) and tightened by a torque wrench (item 1). An axial thrust bearing (item 6) is placed between spindle (item 2) and top of the base block (item 7) to reduce the friction torque coming from the tightening operation. At the other end of the beam, dead load (item 12) is applied by attaching a C-clamp (item 12) and weight pan (item 11).
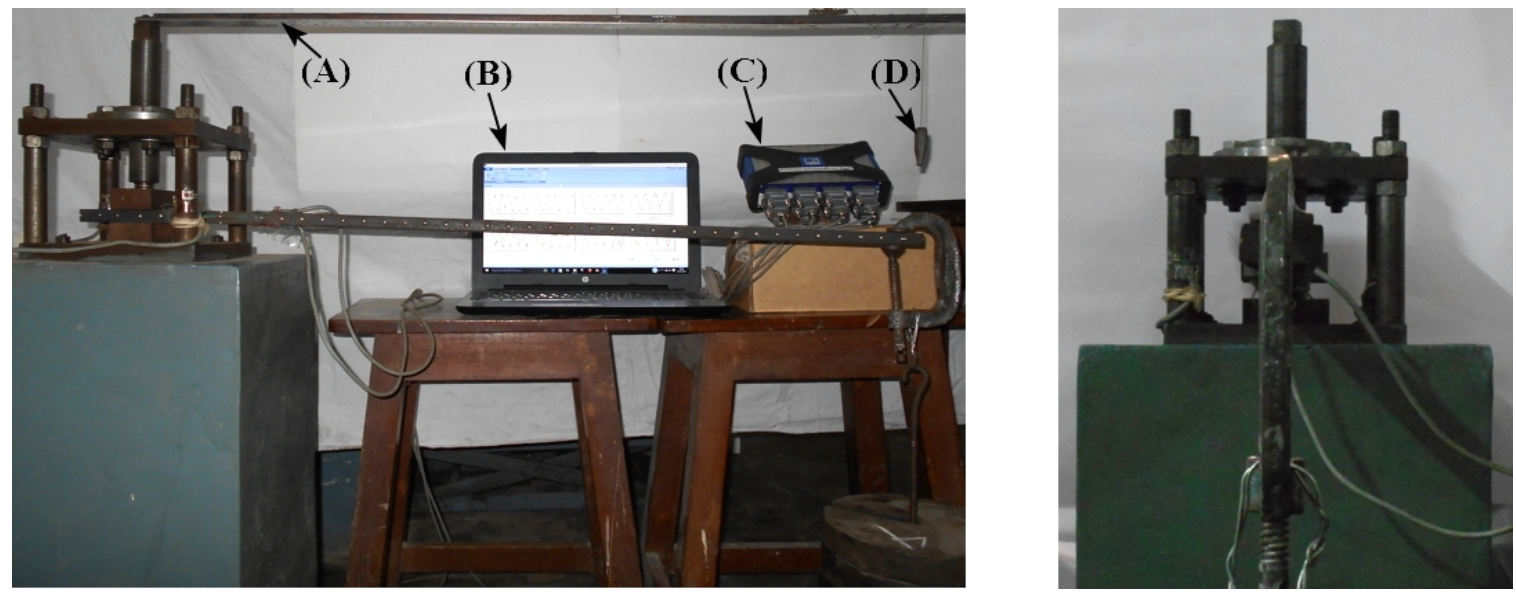

Figure 1. Photograph of experimental set-up (A is horizontal reference scale, B is laptop, C is data acquisition system and $\mathrm{D}$ is a plumb).

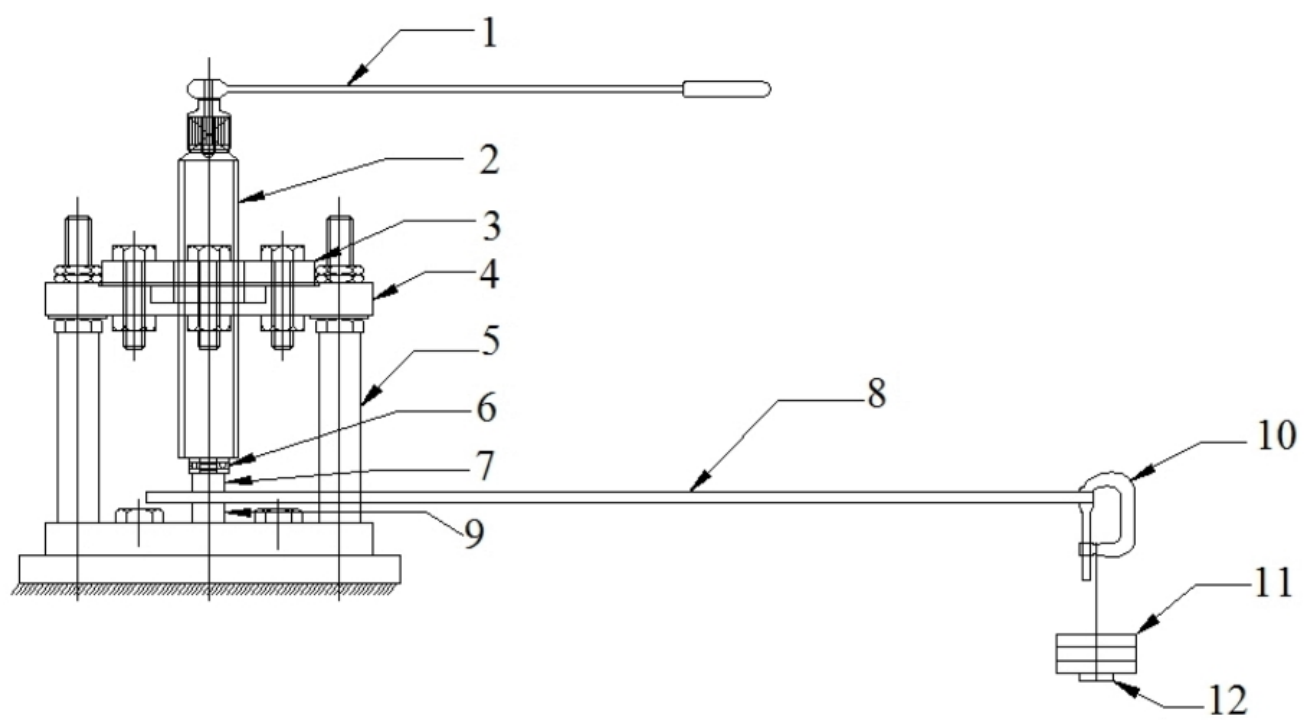

\begin{tabular}{|l|l|l|l|}
\hline Item & Description & Item & Description \\
\hline 1 & Torque Wrench & 7 & Top base block \\
\hline 2 & Spindle & 8 & Cantilever Beam \\
\hline 3 & Circular nut & 9 & Lower base block \\
\hline 4 & Top plate & 10 & C-Clamp \\
\hline 5 & Support structure & 11 & Loads \\
\hline 6 & Axial thrust bearing & 12 & Weight Pan \\
\hline
\end{tabular}

Figure 2. Schematic diagram of the experimental set-up.

For the purpose of experimentation two beam specimens are used, the detail dimensions of which are presented through Fig. 3 and Table 1. These specimens are prepared from commercial steel flat bars made of structural steel $\left(E=200 \mathrm{GPa}, \sigma_{\mathrm{y}}=350 \mathrm{MPa}\right)$. Each of the beam specimens is fixed in the clamping arrangement at two different locations, as shown in Fig. 3a. Such clamping at each of the clamping location divides the beam domain into three regions: free region, clamping 
region and loaded region. Detail dimensions of the beams are given in Table 1, which yield lengths of the three regions as $\left(\mathrm{L}_{\mathrm{f}}=\mathrm{L}_{1}-\mathrm{L}_{\mathrm{c}} / 2\right),\left(\mathrm{L}_{\mathrm{c}}\right)$ and $\left(\mathrm{L}_{\mathrm{e}}-\mathrm{L}_{\mathrm{c}} / 2\right)$ respectively for each beam. Eight strain gauges (SG) are mounted on each of the beams for strain measurement. Their location nomenclatures are shown in the Fig. 3b with respect to the left end of the beam and detail dimensions are presented also in Table 1. Strain gauges 1, 2, 5 and 6 are mounted on top side of the beam and strain gauges 3, 4, 7 and 8 are mounted at the bottom side of the beam. Fixing positions of strain gauges on top and bottom surface are made identical, i.e., strain gauges 3 and 4 are just below strain gauges 1 and 2 respectively and similarly strain gauges 7 and 8 are just below strain gauges 5 and 6 respectively. Strain readings from the first set of SGs are taken for CP1, while the second sets are used for CP2.
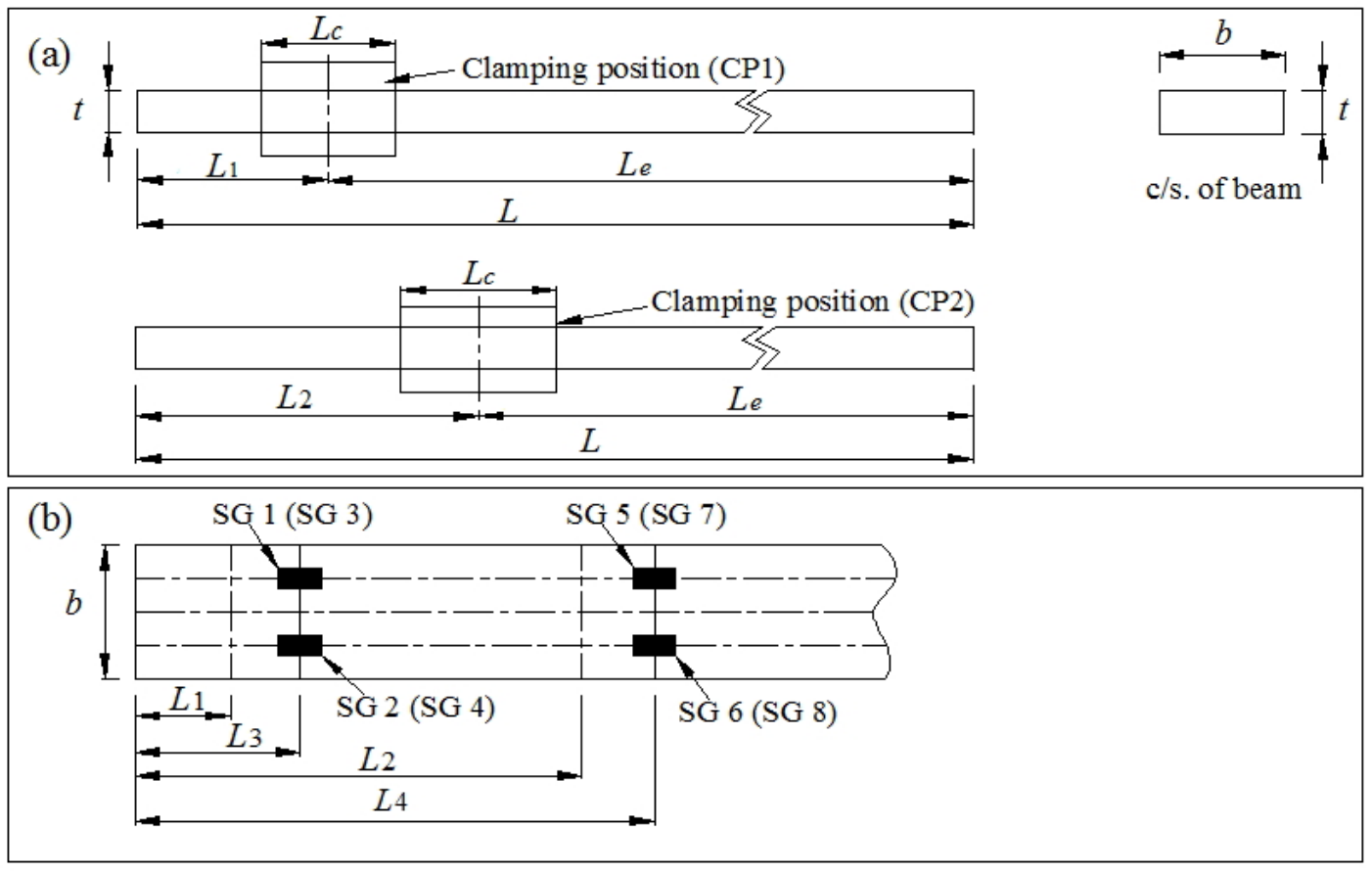

Figure 3. (a) View from front: showing clamping positions of beam and (b) view from top: showing positions of strain gauges on beam.

Table 1. Dimensions of beam regions $(\mathrm{mm})$ at different clamping positions together with strain gauge locations.

\begin{tabular}{|c|c|c|c|c|c|c|c|c|c|c|}
\hline & & $L_{\mathrm{e}}$ & $L$ & $b$ & $t$ & $L_{\mathrm{f}}$ & $L_{1}$ & $L_{2}$ & $L_{3}$ & $L_{4}$ \\
\hline \multirow{2}{*}{ Beam 1} & CP1 & 938.95 & 1015 & 40 & 10 & \multirow{4}{*}{50.7} & \multirow{4}{*}{76.05} & \multirow{4}{*}{177.45} & \multirow{4}{*}{126.75} & \multirow{4}{*}{228.15} \\
\hline & $\mathrm{CP} 2$ & 837.55 & 1015 & 40 & 10 & & & & & \\
\hline \multirow{2}{*}{ Beam 2} & CP1 & 936.95 & \multirow{2}{*}{1013} & \multirow{2}{*}{32} & \multirow{2}{*}{16} & & & & & \\
\hline & CP2 & 835.55 & & & & & & & & \\
\hline
\end{tabular}

Before starting the experiment, permissible load for each beam under each clamping position is calculated using Euler-Bernoulli beam theory. Considering maximum stress as $75 \%$ of the yield stress of beam material, maximum allowable loads are calculated for the two specimens. These loads (in N) are 186.4 and 206 for beam 1 at clamping position 1 and 2. Similarly, the corresponding maximum allowable loads (in N) for beam 2 are 404.2 and 443.4. Slenderness ratio of beam 1 for two different clamping lengths 1 and 2 are 325.26 and 290.13 respectively, whereas the same ratios for beam 2 are 202.85 and 180.4 respectively. As mentioned earlier, the two different beam specimens are clamped under two different clamping positions. Hence total four different specimen settings are created with the two beams. During experimentation, loading is applied through several load steps up to corresponding allowable loads for each of the four settings. Hence, for each of these four different specimen settings, there are 10 to 12 load steps, as shown in 
Table 2. The first load step (load 0) comes from tightening torque, and it is indicated by "clamping" in Table 2. The second load step (load 1) consist of C-clamp and loading pan weight and hence it remains same $(11.77 \mathrm{~N})$ in all the cases. Each of these four settings is experimented with two different torque ratings. So, there are two beams (B1 and B2), each of which are clamped at two different positions (CP1 and $\mathrm{CP} 2)$, with two different torque ratings $(\mathrm{T} 1=3 \mathrm{Kg}-\mathrm{m}$ and $\mathrm{T} 2=14 \mathrm{Kg}$ $\mathrm{m})$. Hence, total eight number of specimen settings are created and these combinations are shown in Table 3.

Table 2. Load steps (N) for different beam settings.

\begin{tabular}{|c|c|c|c|c|}
\hline \multirow{2}{*}{ Load step no. } & \multicolumn{2}{|c|}{ Beam-1 } & \multicolumn{2}{c|}{ Beam-2 } \\
\cline { 2 - 5 } & CP1 & CP2 & CP1 & CP2 \\
\hline 0 & Clamping & Clamping & Clamping & Clamping \\
\hline 1 & 11.77 & 11.77 & 11.77 & 11.77 \\
\hline 2 & 31.39 & 31.39 & 51.00 & 51.00 \\
\hline 3 & 49.05 & 49.05 & 90.2 & 90.2 \\
\hline 4 & 71.12 & 71.12 & 129.5 & 129.5 \\
\hline 5 & 90.25 & 90.25 & 168.7 & 168.7 \\
\hline 6 & 109.76 & 109.76 & 208 & 208.0 \\
\hline 7 & 129.5 & 129.5 & 247.7 & 247.7 \\
\hline 8 & 149.1 & 149.1 & 286.4 & 286.4 \\
\hline 9 & 168.7 & 168.7 & 325.7 & 325.7 \\
\hline 10 & 186.4 & 186.4 & 364.9 & 364.9 \\
\hline 11 & - & 206.0 & 404.2 & 404.2 \\
\hline 12 & - & - & - & 443.4 \\
\hline
\end{tabular}

Table 3. Representation of different specimen settings.

\begin{tabular}{|c|c|c|c|}
\hline 1 & B1 & CP1 & T1 \\
\hline 2 & B1 & CP1 & T2 \\
\hline 3 & B1 & CP2 & T1 \\
\hline 4 & B1 & CP2 & T2 \\
\hline 5 & B2 & CP1 & T1 \\
\hline 6 & B2 & CP1 & T2 \\
\hline 7 & B2 & CP2 & T1 \\
\hline 8 & B2 & CP2 & T2 \\
\hline
\end{tabular}

\section{Deflection Measurement}

Measurement of tip co-ordinate: Measurement of tip coordinate for each set-up under each load step is taken by using a plumb and a $1 \mathrm{~m}$ long steel measurement scale. The scale is used as horizontal reference by setting its origin point aligned with the centre line of spindle. The plumb is dangled from the horizontal levelling scale such that it is just touching the beam tip. Projected length along the horizontal direction is measured directly on the horizontal scale. Whereas, vertical deflection is measured from the beam tip end to the horizontal scale reading point on a simple scale. Tip coordinates of all settings are tabulated in Tables 4 and 5. 
Table 4. Tip coordinate $(x, y)$ of the beam 1 under loaded conditions.

\begin{tabular}{|c|c|c|c|c|c|}
\hline \multirow{2}{*}{$\begin{array}{c}\text { Load step } \\
\text { no. }\end{array}$} & \multirow{2}{*}{ Load step (N) } & \multicolumn{2}{|c|}{ Clamping position 1 } & \multicolumn{2}{c|}{ Clamping position 2 } \\
\cline { 3 - 6 } & & Torque 1 & Torque 2 & Torque 1 & Torque 2 \\
\hline 0 & clamping & $(937,-4)$ & $(937,-4)$ & $(837,-9)$ & $(837,-9)$ \\
\hline 1 & 11.77 & $(937,-10)$ & $(937,-9)$ & $(837,-13)$ & $(837,-12)$ \\
\hline 2 & 31.39 & $(937,-18)$ & $(937,-17)$ & $(836,-18)$ & $(836,-18)$ \\
\hline 3 & 49.05 & $(937,-26)$ & $(937,-25)$ & $(836,-23)$ & $(836,-23)$ \\
\hline 4 & 71.12 & $(937,-34)$ & $(936,-32)$ & $(836,-29)$ & $(836,-28)$ \\
\hline 5 & 90.25 & $(936,-42)$ & $(936,-41)$ & $(836,-36)$ & $(836,-34)$ \\
\hline 6 & 109.8 & $(936,-51)$ & $(936,-49)$ & $(835,-41)$ & $(836,-40)$ \\
\hline 7 & 129.5 & $(935,-59)$ & $(935,-57)$ & $(835,47)$ & $(835,-45)$ \\
\hline 8 & 149.1 & $(935,-65)$ & $(935,-63)$ & $(835,-53)$ & $(835,-50)$ \\
\hline 9 & 168.7 & $(934,-75)$ & $(934,-73)$ & $(835,-58)$ & $(835,-56)$ \\
\hline 10 & 186.4 & $(934,-82)$ & $(934,-79)$ & $(834,-63)$ & $(834,-61)$ \\
\hline 11 & 205.8 & - & - & $(834,-68)$ & $(834,-66)$ \\
\hline
\end{tabular}

Table 5. Tip coordinate $(x, y)$ of beam 2 under loaded conditions.

\begin{tabular}{|c|c|c|c|c|c|}
\hline \multirow{2}{*}{$\begin{array}{c}\text { Load step } \\
\text { no. }\end{array}$} & \multirow{2}{*}{ Load step (N) } & \multicolumn{2}{|c|}{ Clamping position 1 } & \multicolumn{2}{c|}{ Clamping position 2 } \\
\cline { 3 - 6 } & & Torque 1 & Torque 2 & Torque 1 & Torque 2 \\
\hline 0 & clamping & $(935,6)$ & $(935,5)$ & $(836,8)$ & $(836,9)$ \\
\hline 1 & 11.77 & $(935,4)$ & $(935,3)$ & $(836,6)$ & $(836,8)$ \\
\hline 2 & 50.96 & $(935,1)$ & $(935,-1)$ & $(836,4)$ & $(836,5)$ \\
\hline 3 & 90.16 & $(935,-6)$ & $(934,-6)$ & $(836,-1)$ & $(836,0)$ \\
\hline 4 & 129.36 & $(935,-13)$ & $(934,-12)$ & $(836,-5)$ & $(836,-3)$ \\
\hline 5 & 168.56 & $(935,-18)$ & $(934,-18)$ & $(836,-9)$ & $(836,-6)$ \\
\hline 6 & 207.76 & $(935,-24)$ & $(934,-22)$ & $(836,-13)$ & $(836,-10)$ \\
\hline 7 & 247.45 & $(935,-29)$ & $(934,-26)$ & $(836,-18)$ & $(836,-14)$ \\
\hline 8 & 286.16 & $(934,-34)$ & $(934,-31)$ & $(835,-21)$ & $(835,-18)$ \\
\hline 9 & 325.36 & $(934,-39)$ & $(934,-36)$ & $(835,-26)$ & $(835,-21)$ \\
\hline 10 & 364.56 & $(934,-45)$ & $(934,-40)$ & $(835,-30)$ & $(835,-25)$ \\
\hline 11 & 403.76 & $(934,-51)$ & $(934,-45)$ & $(835,-34)$ & $(835,-28)$ \\
\hline 12 & 442.96 & - & - & $(835,-38)$ & $(835,-32)$ \\
\hline
\end{tabular}

Result of tip co-ordinate measurement. Tip deflections of beam for all settings are calculated from loaded tip coordinates (x,y) given earlier in Tables 4 and 5. These tip deflections are plotted against load and presented in Fig. 4. In the plots, solid lines represent linear fitted deflection results corresponding to torque rating 1 and dashed lines correspond deflection results of torque rating 2 .

Measurement of deflection profile: At side face of beam specimens, 40 points in equal divisions are marked along the center line. For each load step, photograph of each loaded beam is captured by using a digital camera and saved in the computer. Few photographs of the loaded cantilever at some specific load steps are shown in Fig. 5. These photographs are used to generate complete deflection profiles of loaded beam under each setting through post processing [28] as described in the following sub-section. In the post-processing technique, the marked points are used for deflection profile measurement, taking tip deflection co-ordinate as the reference. 
Tip deflection w.r.t load

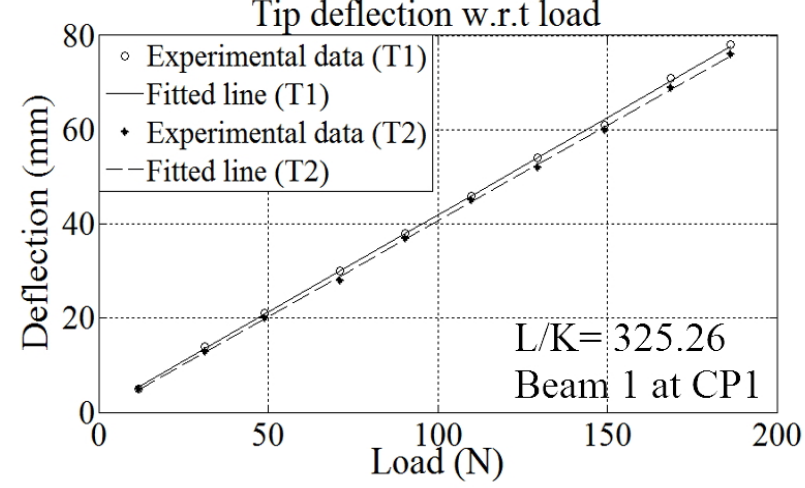

Tip deflection w.r.t load

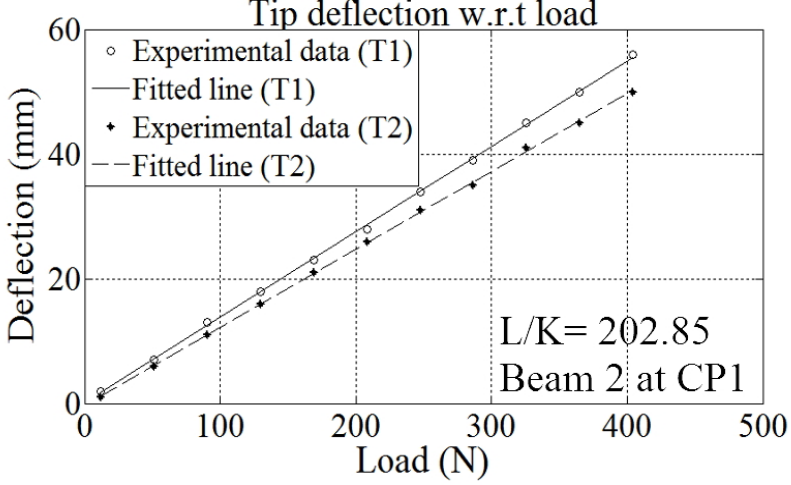

Tip deflection w.r.t load

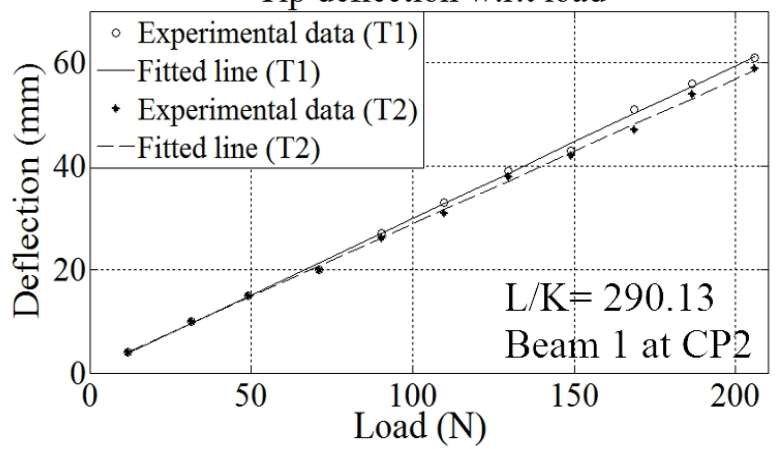

Tip deflection w.r.t load

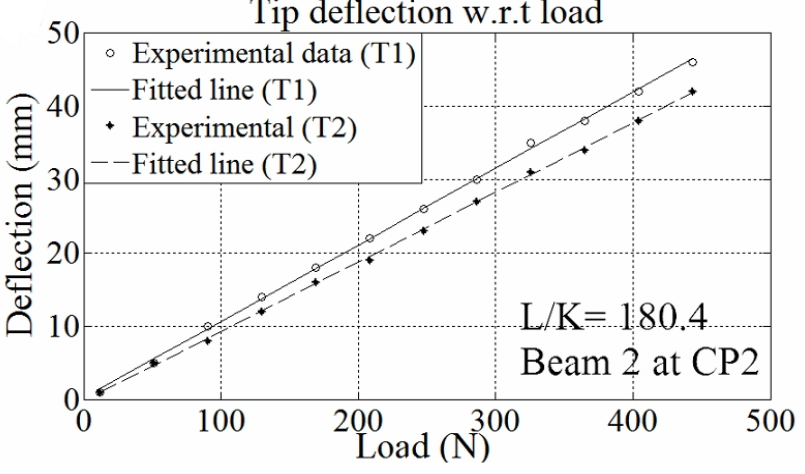

Figure 4. Tip deflection plot of beams at clamping position 1 and 2 under two different torque ratings.

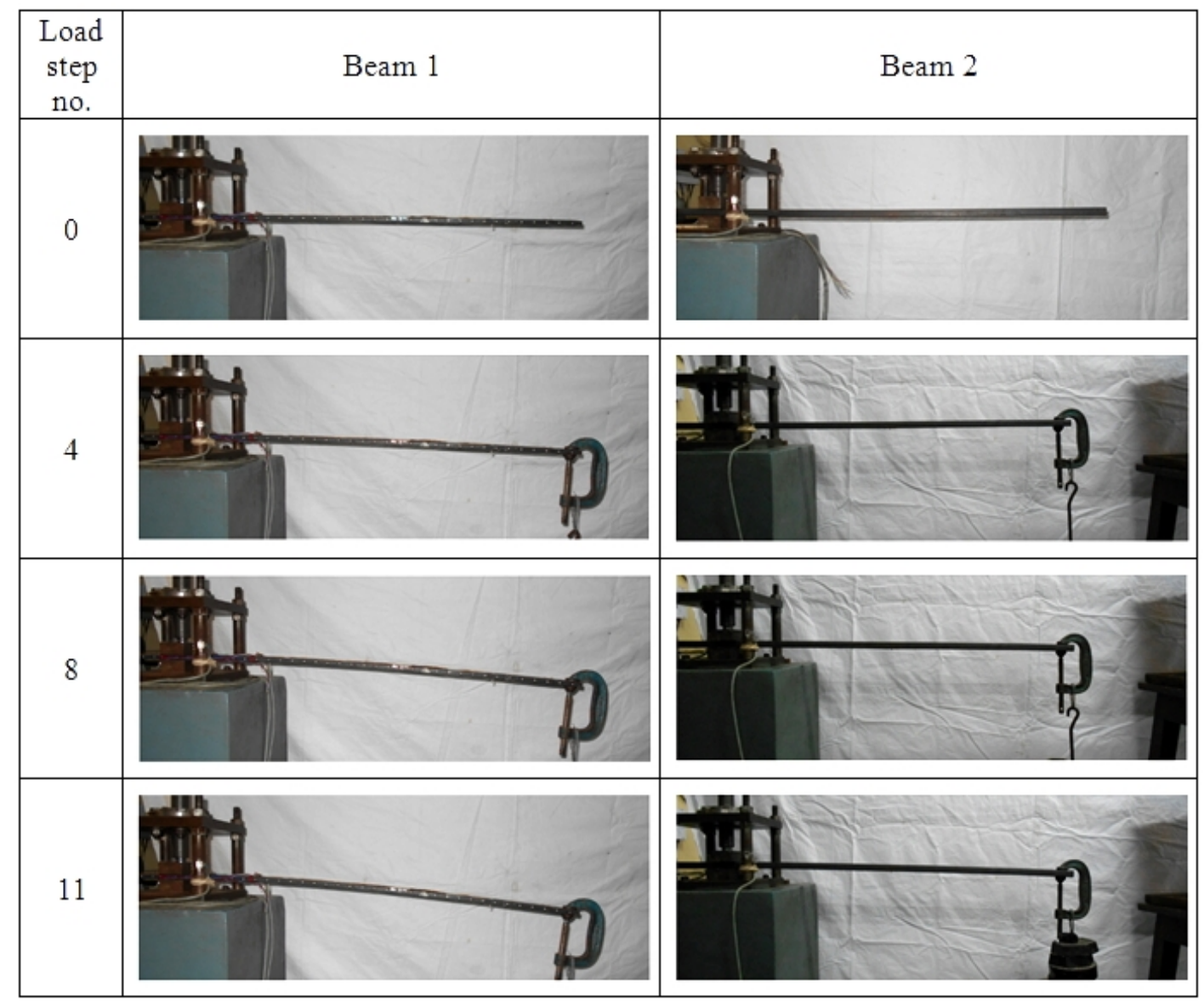

Figure 5. Photograph of deflected beam profiles at clamped position 2 under torque 1 at four specified load steps. 
Results of deflection profile measurement. Now to obtain deflection profiles, each photograph of loaded beam, as shown in Fig. 5 for some loading conditions, is taken in background of AutoCAD® ${ }^{\circledR}$ software. Centre of the clamped point is considered as the origin of the beam profile and new User Co-ordinate System (UCS) is defined at this origin point. Beam profiles are drawn by using a polyline through the marked points and thus yielding center line as reference. The photograph is removed after generation of profile and the drawing is converted into block. In AutoCAD ${ }^{\circledR}$, blocks can be scaled by different ratio along $\mathrm{x}$ and $\mathrm{y}$ directions. This scaling is done with respect to UCS using the tip coordinate data presented in Tables 4 and 5 respectively. After scaling operation, the projected beam length between origin-point to tip end is divided into ten equal divisions. Co-ordinate $(\mathrm{x}, \mathrm{y})$ of each division is identified from the profile in AutoCAD ${ }^{\mathrm{B}}$ using the in-built AutoLISP ${ }^{\circledR}$ software. Using a special purpose AutoLISP ${ }^{\circledR}$ code, these points are saved in an MS Excel ${ }^{\circledR}$ file for each setting under respective loading. Detailed description of the image processing technique used here to obtain loaded beam elastica may be found elsewhere [2, 30]. The MS Excel ${ }^{\circledR}$ files are imported into MATLAB ${ }^{\circledR}$ and deflection profiles of beam under each loaded condition are plotted and shown in Fig. 6. In the figures, solid lines represent deflection profiles under torque rating 1 and dashed lines represent profiles under torque rating 2.
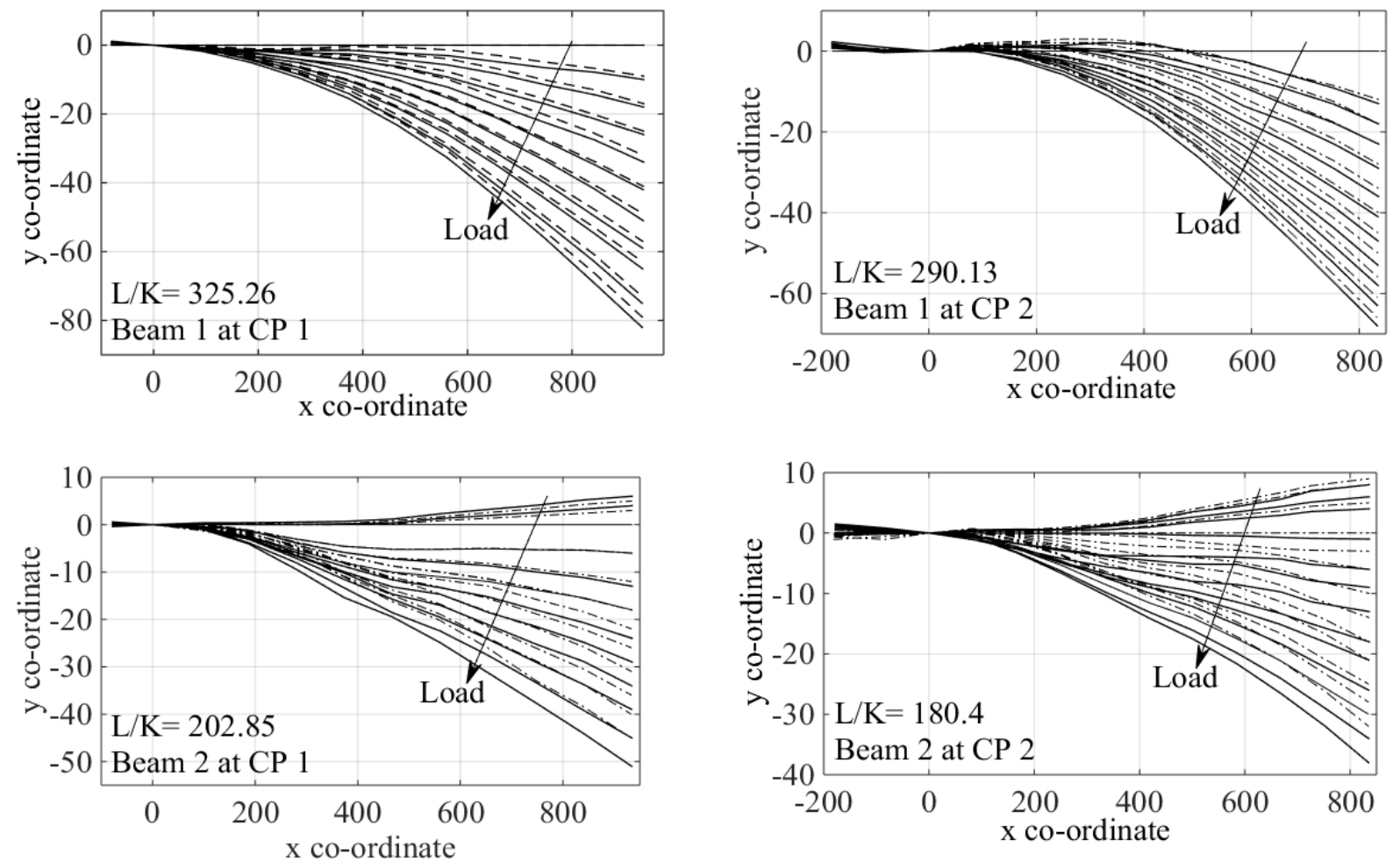

Figure 6. Deflection profiles of beams at clamping position 1 and 2 under two different torque ratings.

It is clear from direct deflection results (Fig. 4) and deflection profiles obtained through image processing (Fig. 6) that deflection is always higher for torque rating 1 than 2 . In addition, it is also obvious from the figures that as beam length decreases and thickness increases, i.e., beam slenderness ratio decreases, deflection difference between torque rating 1 and torque rating 2 increases. It is due to generation of locked-up moment and stress fields at the clamping zone with application of clamping force. These locked-up moment and stress fields resist deflection and hence deflection results corresponding to higher clamping torque (T2) are always lower than those of lower clamping torque (T1). Moreover, effect of the locked-up fields is local for higher slenderness ratio and it affects global deflection behavior more when slenderness ratio is less according to Saint-Venant's principle. 


\section{Strain Measurement}

Two sets of strain gauges are fixed close to the clamped end of the beam, details of which are reported earlier in description of the experimental set-up. These strain gauges are of foil type, made by Tokyo Sokki Kerkyujo Company Limited, with gauge factor- $2.10 \pm 1 \%$, gauge resistance$350 \pm 1.0 \Omega$ and Transverse Sensitivity- $0.3 \%$. Each strain gauge is connected to a data acquisition system MX840B made by HBM with universal amplifier, accuracy class up to $0.05 \%$ and sample rate per channel up to $40 \mathrm{kS} / \mathrm{s}$. The strain gauges are connected in quarter-bridge circuit to the eight channels. The HBM instrument is connected to a Laptop loaded with Catman Easy ${ }^{\circledR}$ software to operate the HBM instrument. The beam specimens are fixed in their corresponding clamping position for the eight settings as mentioned earlier (Table 3). Strain gauge circuits are balanced to zero strain reading at clamped condition of each specimen setting. Afterwards dead loads are applied one by one and strain-time data and plots are obtained in Catman Easy ${ }^{\circledR}$ platform. Such strain-time plot for beam 1 at clamping position 1 under clamping torque 1 is shown in Fig. 7. Now strain reading at each load step of each beam setting is obtained by taking average of portion of strain-time graph corresponding to the particular load step of the particular setting. Enlarged view of portion of strain-time graph corresponding to load step 2 of beam 1 at clamping position 1 under clamping torque 1 is presented as inset plot in Fig. 7. To maintain brevity, strain readings only for beam 1 at clamping position 1 under the two torque ratings are tabulated in Table 6 .

Table 6. Strain reading $(\mu \mathrm{m} / \mathrm{m})$ of beam 1

at clamping position 1 under (a) torque 1 and (b) torque 2 .

\begin{tabular}{|c|c|c|c|c|c|c|c|c|}
\hline \multicolumn{9}{|c|}{ (a) } \\
\hline Step no. & SG1 & SG2 & SG3 & SG4 & SG5 & SG6 & SG7 & SG8 \\
\hline 1 & 85.2 & 85.6 & -86.2 & -85.3 & 71.9 & 70.4 & -72.6 & -71.2 \\
\hline 2 & 237 & 238 & -237 & -235 & 199 & 195 & -200 & -196 \\
\hline 3 & 373 & 373 & -372 & -369 & 311 & 306 & -314 & -307 \\
\hline 4 & 515 & 513 & -510 & -507 & 427 & 420 & -431 & -421 \\
\hline 5 & 663 & 660 & -656 & -652 & 549 & 540 & -554 & -541 \\
\hline 6 & 816 & 813 & -807 & -802 & 676 & 665 & -681 & -665 \\
\hline 7 & 1001 & 989 & -983 & -976 & 823 & 809 & -830 & -811 \\
\hline 8 & 1153 & 1140 & -1131 & -1123 & 948 & 932 & -955 & -932 \\
\hline 9 & 1296 & 1287 & -1277 & -1267 & 1070 & 1052 & -1078 & -1051 \\
\hline 10 & 1432 & 1420 & -1411 & -1399 & 1181 & 1161 & -1189 & -1160 \\
\hline \multicolumn{9}{|c|}{ (b) } \\
\hline Step no. & SG1 & $\mathrm{SG} 2$ & SG3 & SG4 & SG5 & SG6 & SG7 & SG8 \\
\hline 1 & 85.53 & 85.38 & -86.73 & -85.65 & 72.66 & 70.70 & -73.05 & -72.20 \\
\hline 2 & 238.7 & 240.1 & -239.5 & -238.1 & 200.8 & 196.8 & -202.6 & -199.4 \\
\hline 3 & 375.9 & 377.7 & -375.7 & -373.7 & 315.0 & 309.4 & -318.0 & -312.5 \\
\hline 4 & 518.6 & 517.9 & -514.8 & -512.5 & 430.4 & 424.0 & -435.9 & -427.9 \\
\hline 5 & 670.9 & 665.8 & -661.0 & -658.4 & 549.4 & 544.5 & -559.4 & -548.5 \\
\hline 6 & 825.3 & 812.5 & -805.9 & -802.5 & 669.4 & 664.4 & -681.9 & -668.5 \\
\hline 7 & 1004 & 983.1 & -974.5 & -969.8 & 807.6 & 803.0 & -823.7 & -807.4 \\
\hline 8 & 1153 & 1132 & -1122 & -1116 & 930.2 & 924.4 & -947.9 & -928.9 \\
\hline 9 & 1295 & 1279 & -1268 & -1261 & 1054 & 1044 & -1071 & -1049 \\
\hline 10 & 1431 & 1412 & -1399 & -1392 & 1164 & 1152 & -1181 & -1156 \\
\hline
\end{tabular}




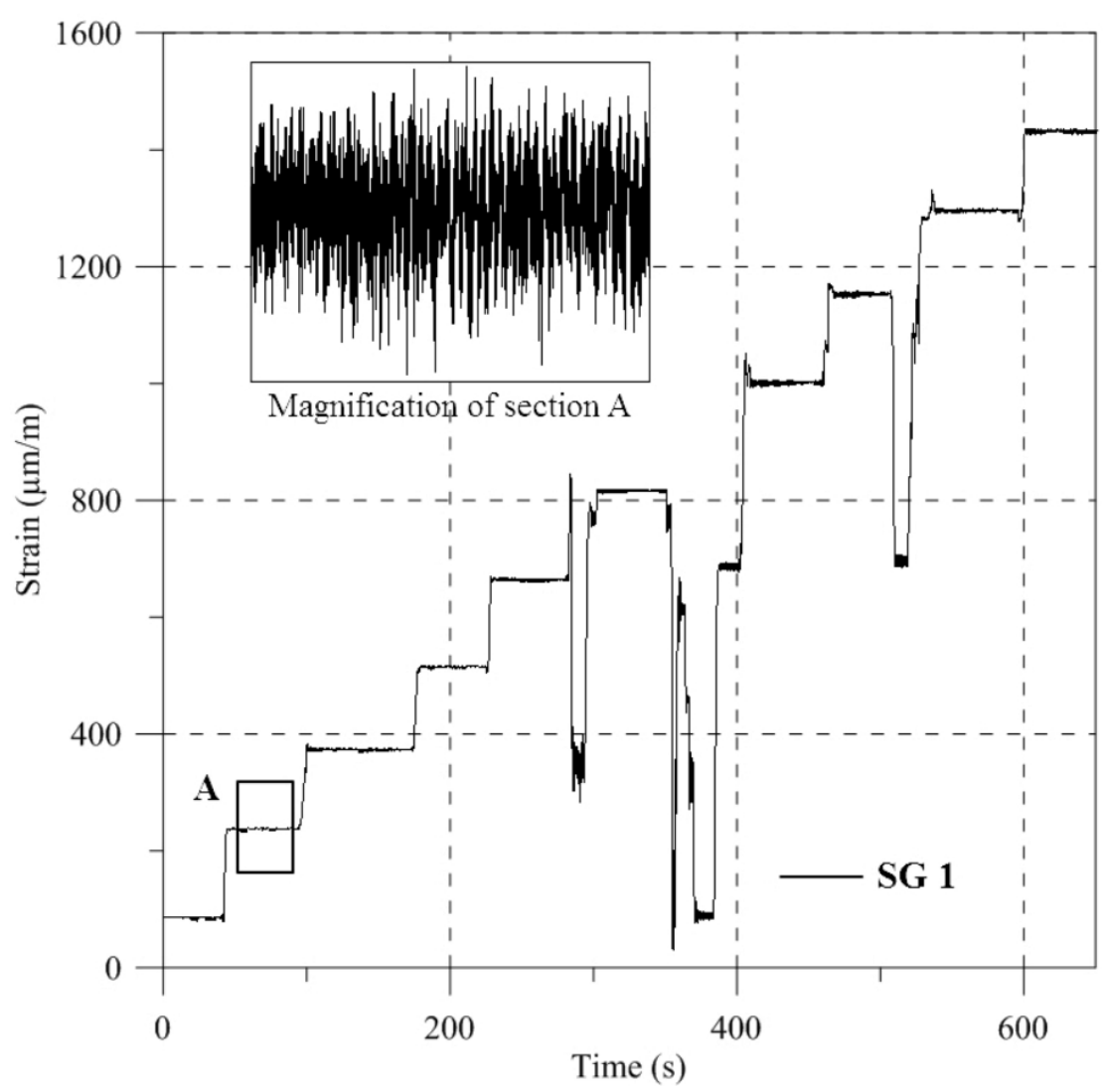

Figure 7. Strain-time plot for B1, CP1, T1 at all load step.

Strain measurement result: Strain values presented in Table 6 for beam 1 at clamping position 1 are plotted against load and shown in Fig. 8. All the load-strain plots have linear trends indicating small strain operating regime. However, difference between the strain results of same strain gauge for different torque ratings is not clearly visible in Fig. 8. Hence, load-strain graphs for SG1 and SG2 under the different torque ratings are magnified at section B and shown as inset plot in the figure. From the visualization of section B and strain data of Table 6, it is hard to identify regular trend of clamping effect on strain results. It may be the reason that after applying the clamping torque strain gauge circuits are balanced every time. Hence, strain gauge results show zero strain values at clamped conditions and effect of clamping torque is not manifested in the strain results.

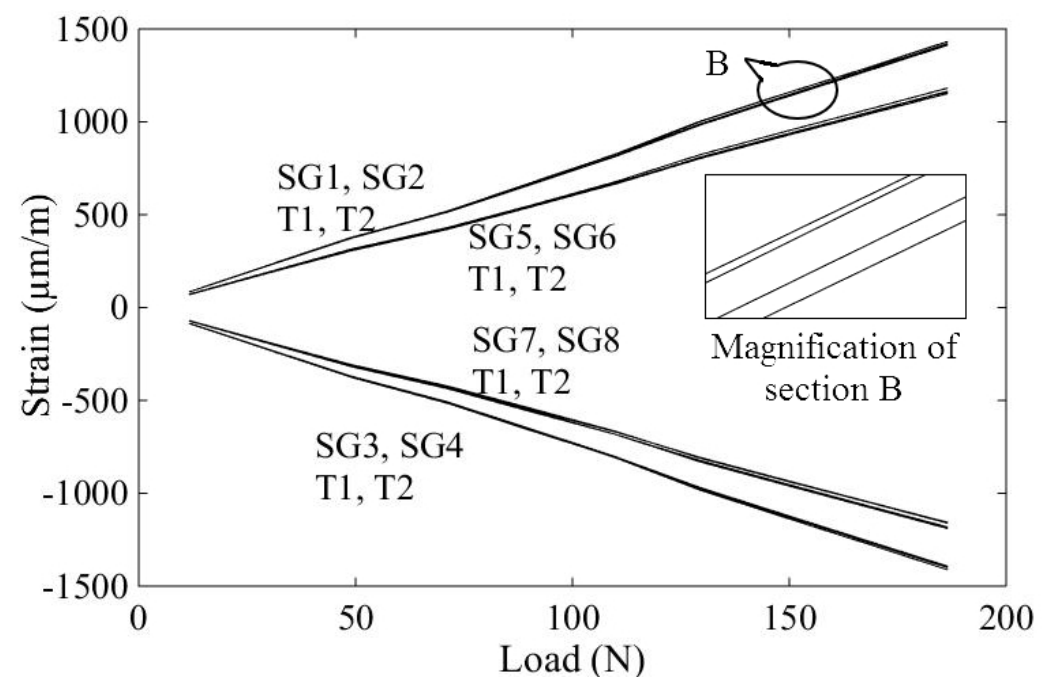

Figure 8. Strain-load plot for B1, CP1 at all load step and magnified section B. 


\section{Vibration Frequency Measurement}

For the purpose of vibration frequency measurement, all strain gauges are again connected to the same HBM instrument as described in the previous section. After application of required clamping torque and dead load, a small impact force is applied at the suitable location of the beam and strain-time plots are captured from the HBM instrument using Catman Easy ${ }^{\circledR}$. An accelerometer was also mounted on beam but it could not capture signal from vibrating loaded beam due to very low frequencies and hence accelerometer readings are not further considered. Strain-time plot for beam 1 at clamping position 1 under torque 1 is shown in Fig. 9a. Strain-time plots corresponding to all the settings are exported into MS Excel ${ }^{\circledR}$ data files in Catman Easy ${ }^{\circledR}$ software. These MS Excel ${ }^{\circledR}$ data files are imported into MATLAB ${ }^{\circledR}$ and the time domain plots are converted to frequency domain plots using FFT function. FFT plot corresponding to Fig. 9a is shown in Fig. 9b. First two natural frequencies $\left(f_{1}\right.$ and $\left.f_{2}\right)$ are obtained from the FFT plots of SG5 for all settings and these frequencies are tabulated in Table 7.

Table 7. (a) First natural frequencies $(\mathrm{Hz})$ and (b) second natural frequencies $(\mathrm{Hz})$ of all settings for strain gauge 5 .

\begin{tabular}{|c|c|c|c|c|c|c|c|c|}
\hline \multicolumn{9}{|c|}{ (a) } \\
\hline \multirow{2}{*}{$\begin{array}{c}\text { Load } \\
\text { step no. }\end{array}$} & \multicolumn{8}{|c|}{ Beam settings (as in table 3 ) } \\
\hline & 1 & 2 & 3 & 4 & 5 & 6 & 7 & 8 \\
\hline 0 & 9.375 & 9.375 & 11.72 & 12.01 & 14.06 & 14.65 & 16.99 & - \\
\hline 1 & 5.273 & 5.566 & 6.738 & 6.738 & 9.082 & 9.375 & - & 11.28 \\
\hline 2 & 3.808 & 3.808 & 4.687 & 4.687 & 5.273 & 5.566 & - & 6.443 \\
\hline 3 & 3.515 & 3.222 & 4.101 & 4.101 & 4.101 & 4.394 & 4.687 & 5.273 \\
\hline 4 & 2.929 & 2.929 & 3.515 & 3.515 & 3.515 & 3.515 & 4.101 & 4.394 \\
\hline 5 & 2.343 & 2.636 & 2.929 & 2.929 & 3.222 & 3.223 & 3.515 & 3.808 \\
\hline 6 & 2.343 & 2.343 & 2.636 & 2.636 & 2.929 & 2.930 & 3.222 & 3.515 \\
\hline 7 & - & 2.343 & 2.344 & 2.636 & 2.636 & 2.636 & 3.076 & - \\
\hline 8 & 2.051 & 2.050 & 2.344 & 2.343 & 2.636 & 2.636 & 2.929 & 2.929 \\
\hline 9 & 1.757 & 1.757 & 2.344 & 2.343 & 2.344 & 2.344 & 2.636 & 2.929 \\
\hline 10 & - & 1.757 & 2.343 & 2.050 & 2.344 & 2.343 & 2.636 & 2.636 \\
\hline 11 & - & - & 2.050 & 2.050 & 2.051 & 2.051 & 2.636 & 2.636 \\
\hline 12 & - & - & - & - & - & - & 2.490 & 2.343 \\
\hline \multicolumn{9}{|c|}{ (b) } \\
\hline \multirow{2}{*}{$\begin{array}{c}\text { Load } \\
\text { step no. }\end{array}$} & \multicolumn{8}{|c|}{ Beam settings (as in table 3 ) } \\
\hline & 1 & 2 & 3 & 4 & 5 & 6 & 7 & 8 \\
\hline 1 & 43.94 & - & - & - & - & - & - & - \\
\hline 2 & - & 41.60 & - & - & 58.00 & - & - & - \\
\hline 3 & 41.01 & 41.31 & 49.80 & - & 57.13 & 60.35 & 69.14 & 73.83 \\
\hline 4 & 39.84 & 41.01 & 50.39 & 50.39 & - & - & 69.72 & - \\
\hline 5 & - & 40.43 & 49.51 & 49.22 & - & - & 70.31 & 73.82 \\
\hline 6 & 39.84 & 40.43 & 50.09 & 48.63 & - & 60.35 & 70.89 & 73.82 \\
\hline 7 & - & 40.43 & 49.80 & 49.51 & - & 61.23 & 71.04 & - \\
\hline 8 & 40.13 & 40.43 & 50.09 & 49.80 & - & 61.52 & 71.77 & - \\
\hline 9 & 39.55 & 40.43 & 49.80 & 49.80 & - & - & 72.36 & 74.41 \\
\hline 10 & - & 40.43 & 50.09 & 49.80 & 60.35 & 62.40 & 73.24 & - \\
\hline 11 & - & - & 50.39 & 50.09 & 60.64 & 62.40 & 73.53 & 75.00 \\
\hline 12 & - & - & - & - & - & - & - & 75.88 \\
\hline
\end{tabular}



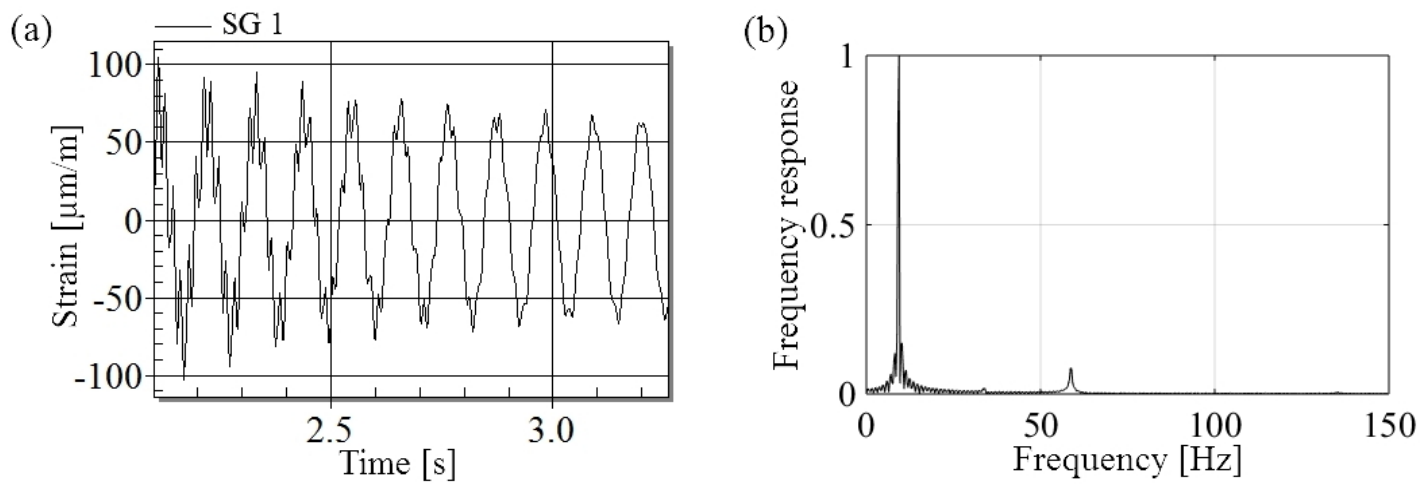

Figure 9. (a) strain-time plot for B1, CP1, T1 at load step 0 and (b) FFT plot.

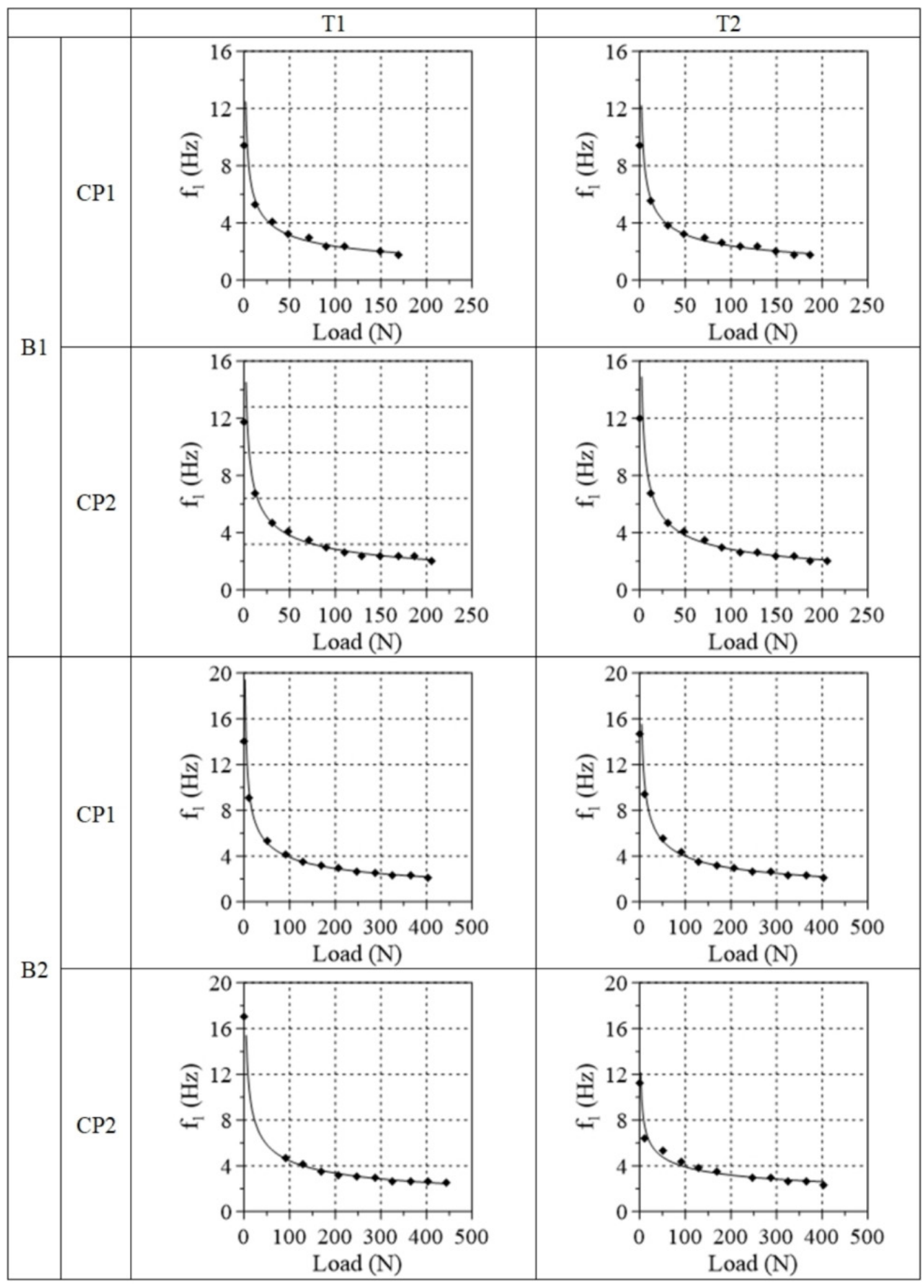

Figure 10. First natural frequencies for all settings. 


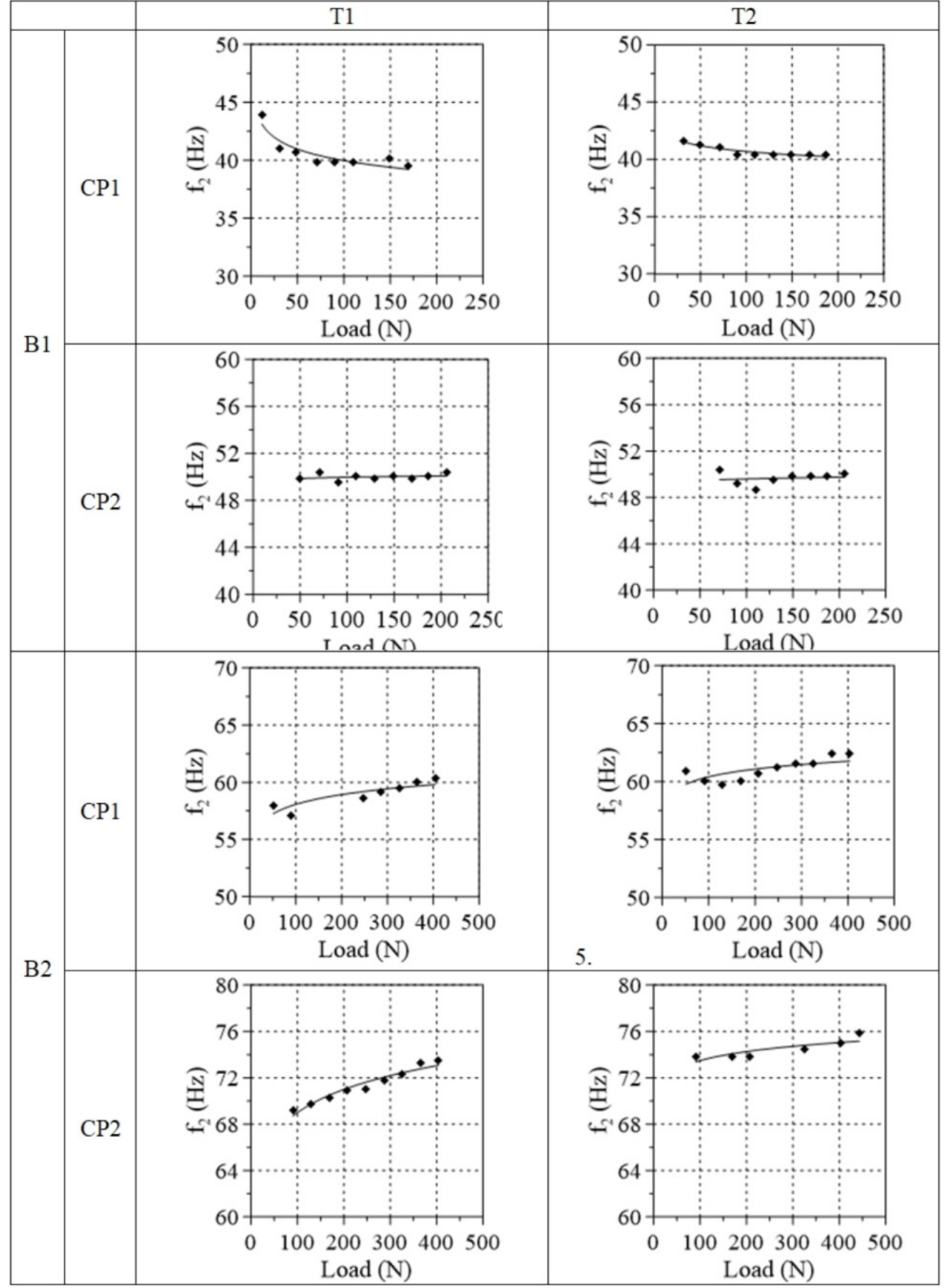

Figure 11. Second natural frequencies for all settings.

Vibration frequency measurement result: Data of first two natural frequencies of loaded cantilever beam as tabulated in Table 7 are plotted with load for the corresponding setting and shown in Figs. 10 and 11 respectively. In these figures, dotted points represent experimental data (Table 7) and solid lines represent the best-fitted curve. Fig. 10 is showing an obvious decreasing trend of variation of first natural frequency with load. Whereas, there is no regular trend for second natural frequency. One reason for such irregularity is due to data insufficiency in Table $7 \mathrm{~b}$ which occurs in measurement of second natural frequency due to unavoidable noise created by vibrating dead loads placed loosely one on top of another. As it is obvious from Table $7 \mathrm{~b}$ that this problem is more prominent at lower load steps, i.e., at higher frequency range. Another possible reason of irregular trends of second natural frequencies with load may be due to interactions of multiple modes at different load levels. Hence for clear understanding of the phenomenon, mode shapes of 
the beam in the second vibrating mode need to be analyzed. As experimental mode shapes are not available with the present experimental set-up, theoretical mode shapes in second vibrating mode are obtained by modeling the beam as cantilever beam with lumped mass at tip. Governing equation is obtained using Hamilton's principle considering combined bending and stretching and nonlinear free vibration problem is solved in MATLAB ${ }^{\circledR}$ software and mode shapes in second mode under loaded conditions are shown in Fig. 12. The figure clearly indicates that node point in the beam domain gradually moving towards tip of the beam domain with increasing static loading.

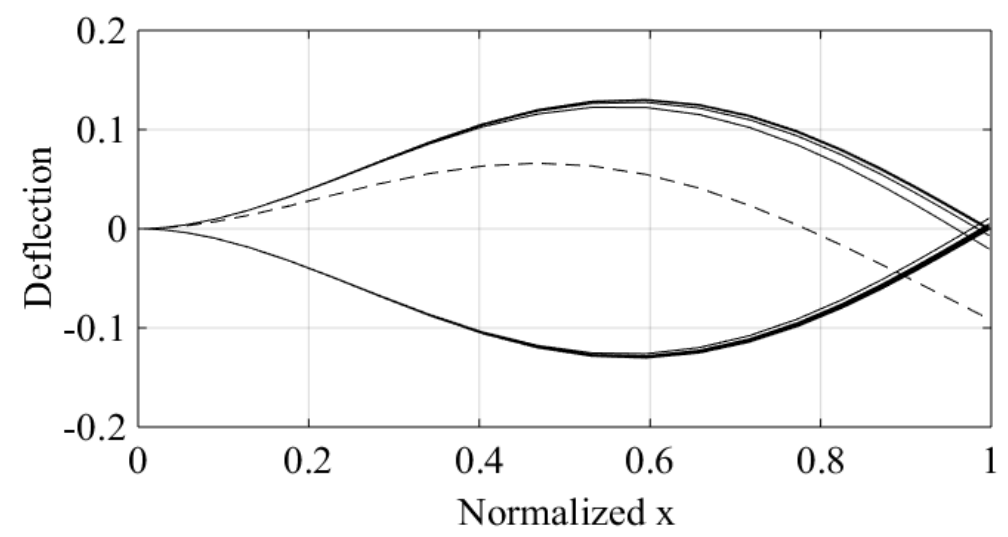

Figure 12. Mode shapes of loaded cantilever beam (dashed line indicates no-load condition) in second vibrating mode.

Effect of clamping torque on loaded natural frequency $\left(f_{1}\right.$ and $\left.f_{2}\right)$ of cantilever beam is not obvious from Figs. 10 and 11. But it is obvious from data points of Table $7 \mathrm{a}$ that as slenderness ratio decreases effect of clamping on first natural frequency is slightly visible, i.e., $f_{1}$ is slightly more for higher clamping torque rating than the lower clamping torque. Such effect is prominent at lower load steps and as dead load is increasing the natural frequencies for both the torque ratings become almost equal. To delve inside the phenomenon, experimental mode shapes of vibrating beams under each of the loaded conditions need to be captured. In addition, mathematical model of the experimental clamped beam system need to be developed that deals with the same question. However, observations on mode shapes of loaded vibrating beam are not possible with the present experimental set-up and the mentioned theoretical analysis is out of scope of the present paper, and hence it is left as the future scope of the present work.

\section{Conclusions}

Effect of finite clamping on static and dynamic behavior of clamped free beam has been studied experimentally. Experiment is carried with four different beam settings with different slenderness ratios. Specimens at each of these four settings are clamped under two different torque rating. Deflections under static load are measured directly at tip point, whereas deflection profiles are obtained through post processing of photographs of loaded beams. Strain responses of the beams under static load and loaded natural frequencies under each static loading subjected to free vibrations are observed using strain gauge sensors. It is obvious from experimental results that static deflections of clamped beams have decreasing trends with clamping torque under each setting. Or in other words, the locked-up fields developed in clamping region resist deformation of clamped structures. Moreover, such effect of finite clamping on deformation characteristics becomes more prominent for lower slenderness ratio. Individual static strain response for beam under each setting is found linear with loading. However, no obvious trend for clamping effect on static strain response has been observed. Similarly when strain gauge signals are used for dynamic responses, clamping effect is also not observed. However, first loaded natural frequencies have obvious decreasing trends with increasing static loading. In case of second natural frequencies, the trends are irregular indicating interactions of multiple modes at higher dead loads. The present study calls for 
a more precise experimentation to capture complete dynamic characteristics including mode shapes of loaded vibrating beams. The experimental results are reported in suitable manner which will facilitate to undertake theoretical modeling of clamped structures incorporating clamping effect.

\section{Conflict of Interest}

The authors declare that there is no conflict of interest.

\section{References}

[1] K.E. Bisshopp, D.C. Drucker, Large deflection of cantilever beams, Q. Appl. Math. 2 (1945) $272-275$.

[2] S. Ghuku, KN. Saha, A theoretical and experimental study on geometric nonlinearity of initially curved cantilever beams, Eng. Sci. Technol. Int. J. 19(1) (2016) 135-146.

[3] S. Ghuku, KN. Saha, An experimental study on stress concentration around a hole under combined bending and stretching stress field, Proc. Tech. 23 (2016) 20-27.

[4] T. Beléndez, C. Neipp, A. Beléndez, Numerical and experimental analysis of a cantilever beam: A laboratory project to introduce geometric nonlinearity in mechanics of materials, Int. J. Eng. Educ.19 (2003) 885-892.

[5] R.B. Charde, D.V. Bhope, Investigation of stresses in master leaf spring by fem and its experimental verification, Int. J. Eng. Sci. Technol. 4(2) (2012) 633-640.

[6] H.B. Motra, J. Hildebrand, A. Dimmig-Osburg, Assessment of strain measurement techniques to characterise mechanical properties of structural steel, Eng. Sci. Technol. Int. J. 17(4) (2014) 260-269.

[7] H. Ahuett-Garza et al., Studies about the use of semicircular beams as hinges in large deflection planar compliant mechanisms, Precis. Eng. 38(4) (2014) 717-727.

[8] P.F. Pai, T.J. Anderson, E.A. Wheater, Large-deformation tests and total-Lagrangian finite element analyses of flexible beams, Int. J. Solids Struct. 37(21) (2000) 2951-2980.

[9] F. Mujika, On the effect of shear and local deformation in three-point bending tests, Polym. Test. 26(7) (2007) 869-877.

[10] A. Dorogoy, D. Rittel, Transverse impact of free-free square aluminium beams: An experimental-numerical investigation, Int. J. Impact Eng. 35(6) (2008) 569-577.

[11] L.A. Parnell, M.H. Cobble, Lateral displacement of a vibrating cantilever beam with a concentrated mass, J. Sound Vib. 44(4) (1975) 499-511.

[12] P.A.A. Laura, J.L. Pombo, E.A. Susemihl, A note on the vibrations of a clamped-free beam with a mass at the free end, J. Sound Vib. 37(2) (1974) 161-168.

[13] J. Blachut, A note on optimal design of a beam with a mass at its end, J. Sound Vib. 82(2) (1982) 203-208.

[14] Y.U. Chen, On the vibration of beams or rods carrying a concentrated mass, J. Appl. Mech. 30(2) (1963) 310-311.

[15] S.W. Prashant, V.N. Chougule, A.C. Mitra, Investigation on modal parameters of rectangular cantilever beam using Experimental modal analysis, Mater. Today-Proc. 2 (2015) 2121-2130.

[16] D.R. Prasad, D.R. Seshu, A study on dynamic characteristics of Structural materials using modal analysis, Asian J. Civil Eng. 9(2) (2008) 141-152.

[17] I.P. Krishna, C. Padmanabhan, Experimental and numerical investigation of impacting cantilever beams: Second mode response, Int. J. Mech. Sci. 92 (2015) 187-193. 
[18] N. Lasowicza, R. Jankowski, Experimental and numerical analysis of an aluminium cantilevered beam with polymer adhesive, Procedia Eng. 172 (2017) 634-639.

[19] S. Ilyas et al., An experimental and theoretical investigation of electrostatically coupled cantilever microbeams, Sensor Actuat. A-Phys. 247 (2016) 368-378.

[20] M. Armandei, I.F. Darwish, K. Ghavami, Experimental study on variation of mechanical properties of a cantilever beam of bamboo, Constr. Build Mater. 101 (2015) 784-790.

[21] J.D. Hobeck, D.J. Inman, Dual cantilever flutter: Experimentally validated lumped parameter modeling and numerical characterization, J. Fluid Struct. 61 (2016) 324-338.

[22] A.M. Wahrhaftig, R.M.L.R. Brasil, Representative experimental and computational analysis of the initial resonant frequency of largely deformed cantilevered beams, Int. J. Solids Struct. 102(103) (2016) 44-55.

[23] T.J. Anderson, A.H. Nayfeh, B. Balachandran, Experimental verification of the importance of the nonlinear curvature in the response of a cantilever beam, J. Vib. Acoust. 118(1) (1996) $21-27$.

[24] Z. Zembaty et al., Strain sensing of beams in flexural vibrations using rotation rate sensors, Sensor Actuat. A-Phys. 269 (2014) 322-330.

[25] K. Ikeda et al., Silicon pressure sensor integrates resonant strain gauge on diaphragm, Sensor Actuat. A-Phys. 21(1-3) (1990) 146-150.

[26] A. Djordjevich, M. Boskovic, Curvature Gauge, Sensor Actuat. A-Phys. 51 (1996) 193-198.

[27] H. Xiao, H. Li, J. Ou, Strain sensing properties of cement-based sensors embedded at various stress zones in a bending concrete beam, Sensor Actuat. A-Phys. 167 (2011) 581-587.

[28] J. Zhou et al., Coupled bending and torsional vibrations of non-uniform thin-walled beams by the transfer differential transform method and experiments, Thin Walled Struct. 127 (2018) 373-388.

[29] T. Roncen, J.J. Sinou, J.P. Lambelin, Non-linear vibrations of a beam with non-ideal boundary conditions and uncertainties-Modeling, numerical simulations and experiments, Mech. Syst. Sig. Process. 110 (2018) 165-179.

[30] S. Ghuku, KN. Saha, Large deflection analysis of curved beam problem with varying curvature and moving boundaries, Eng. Sci. Technol. Int. J. 21(3) (2018) 408-420. 